\title{
O CONCEITO DE EXTRA-CAMPO NO CINEMA: O PLANO DO INVISÍVEL ${ }^{1}$
}

\section{THE CONCEPT OF THE EXTRA-FIELD IN CINEMA: THE INVISIBLE PLANE}

\author{
Ricardo Weschefelder \\ Doutorando em Ciências da Comunicação pela Universidade do Vale dos Sinos \\ Mestre em Literatura pela Universidade Federal de Santa Catarina \\ Graduado em Cinema pela Universidade do Sul de Santa Catarina \\ Professor da Uniasselvi/Asevim e Unifebe \\ E-mail: ricavertice@yahoo.com.br
}

\section{RESUMO}

Neste artigo procuramos ampliar a discussão sobre o conceito do extra-campo no cinema. O plano cinematográfico, seja em enquadramento fixo ou móvel, é o território que promove a dialética entre o interior e exterior da cena. A nossa discussão é sob a perspectiva do simbólico, em diálogo com Walter Benjamin, vendo o plano como camada, estado e dimensão da imagem. Esta outra dimensão - seu plano invisível - parece que, se mostra a ver, mais em função do tempo do que do espaço. O espaço tende a reduzir e confinar a imagem em seu território demarcado. O tempo, por outro lado, pode criar noções entre passado, presente e futuro no plano da imagem. O tempo intrínseco da narrativa faz com que os quadros retornem de outra maneira, remetam a outros quadros e, sobretudo, deixem rastros na passagem das imagens e dos sons em movimento.

Palavras-chave: Cinema. Invisível. Rastros. Olhares.

\begin{abstract}
In this article we seek to expand the discussion about the concept of the extra-field in cinema. The cinematographic plane, whether in fixed or mobile framing, is the territory that promotes the dialectic between the interior and exterior of the scene. Our discussion is under the perspective of the symbolic, in a dialog with Walter Benjamin, seeing the plane as a layer, state and dimension of the image. This other dimension - its invisible plane - appears to reveal itself more in function of time than of space. Space tends to reduce and confine the image in its marked territory. Time, on the other hand, can create notions between past, present and future in the plane of the image. The intrinsic time of the narrative causes the frames to return in another manner, to relate to other frames and above all to leave tracks in the passage of the images and sounds in movement.
\end{abstract}

Key-words: Cinema. Invisible. Traces. Looks. 


\section{INTRODUÇÃO}

A discussão aqui apresentada insere-se dentro dos estudos sobre audiovisualidades nas mídias que têm seu foco de pesquisa na atualização do audiovisual em relação à sua significação, produção e consumo e capacidade de gerar novas culturas (PARENTE, 1996; MACHADO, 2007; KILPP, 2008, 2010).

Neste artigo, especificamente, discutimos o conceito de extra-campo no cinema no interior de uma abordagem que procura entender o tensionamento dialético entre o ambiente dentro e fora do plano cinematográfico. Este conceito recebe diferentes denominações e está intrinsecamente ligado ao conceito de plano, que faz parte do vocabulário técnico de audiovisual e corresponde, estritamente, à imagem enquadrada e situada entre dois cortes. O conceito de extra-campo suscitou e suscita inúmeras formulações e debates, tanto de cineastas como de teóricos de cinema, que vão de Balazs (1992) a Bonitizer (2007), passando por Eisenstein (2002), Bazin (1991) e Deleuze (1989, 2005).

Discutimos o conceito de extra-campo a partir de dois outros conceitos: "rastros" e “aura”, presentes na obra do filósofo alemão Walter Benjamin (1892-1940) (2007). A aura e, principalmente, o rastro, são alegorias de Benjamin para a percepção do tempo, ou melhor, para a trama de espaço e tempo nas imagens, que se perdem e tornam a reencontrar-se em diferentes contextos narrativos. Trabalhamos com a ideia de "dupla distância" do olhar, proposta pelo benjaminiano Didi-Huberman (2010), que vem a ser a aparição do tempo sobre as imagens, o jogo de distância entre o espaço e o tempo, figurados em aura (imagem longínqua) e rastro (imagem próxima). O conceito de rastro é utilizado para entender o plano cinematográfico como imagem de limiar que confunde o dentro e o fora na arquitetura do quadro e promove a miragem entre os tempos.

\section{ONDE A IMAGEM ACABA NO CINEMA? ESTADO DA ARTE}

O tema do extra-campo não é novo nos estudos de audiovisual. Encontramos menções a este conceito em estudos que abordam, por exemplo, a ontologia da imagem (BAZIN, 1991), a relação entre teatro e cinema (XAVIER, 2008), pintura e cinema (AUMONT, 2004), as máquinas de captação de imagens (DUBOIS, 2006) e as novas mídias (MACHADO, 2011). De todo modo, o tema sempre foi abordado de forma transversal, sem maiores preocupações em aprofundamentos teóricos e metodológicos. Não há consenso, tampouco, quanto à sua nomenclatura. Aumont (2004) chama-o de "fora-de-quadro" para assinalar a herança com o quadro pictórico; Burch (1992) denomina-o de "espaço-off”, na tentativa de estabelecer o espaço dentro (concreto) e fora 
da tela (imaginário); Deleuze (1989) fala em "extra-campo", tratando o campo, ou seja, a imagem enquadrada, como um conjunto fechado que se abre para sistemas mais vastos de conjuntos, de novos extra-campos infinitos.

O Dicionário de Imagem (2011, p. 172) conceitua "fora de campo" como tudo o que "não aparece na imagem e pode ser imaginariamente situado à esquerda, à direita, em baixo, em cima, à frente e atrás do campo", já o "fora de quadro" é o espaço reservado à elaboração da obra, à equipe técnica e a produção do filme.

Neste item realizamos o estado da arte para destacar autores e pesquisadores que se referem, direta e indiretamente, ao extra-campo, ou seja, procuramos trazer os rastros de autores que passaram pelo objeto em análise. Adotamos para o recorte neste texto, os seguintes critérios: primeiro, um conjunto de teóricos do campo estético e de cinema que escreveram sobre o extra-campo; em seguida, um conjunto de pesquisas, de mestrado e de doutorado, que tratam de temas correlatos ao extra-campo e, por fim, reflexões de cineastas sobre o tema em foco.

Segundo o crítico de artes e ensaísta norte-americano Crary (2004), em fins do século XIX a atenção torna-se objeto central de estudo em diversos campos do conhecimento - como filosofia e psicologia, por exemplo - em consequência da ampliação dos estímulos visuais da então vida moderna e pela consciência de que o corpo produz subjetividades e exerce maior influência na apreensão dos sentidos. Crary analisa os quadros do pintor Manet (1832-1883), que segundo ele, oscilam entre dois pólos estéticos divergentes da cultura moderna: a integridade do campo visual e a dissolução dos elementos visuais presentes no quadro. Segundo ele, nas obras de Manet, existe a tensão entre o interior e o exterior do quadro, seja na sugestão dos olhares para fora do quadro, seja na fluidez dos movimentos ou nos detalhes dos gestos.

Ao analisar a organização e atenção do olhar nos primórdios do cinema, o psicólogo alemão Münsterberg (1863-1916) conclui que a imagem é percebida de forma homogênea: "ela é a mesma de qualquer canto da sala" (2008, p. 29), e o que a câmera faz é, justamente, organizar e hierarquizar a atenção, algo que, anteriormente, era função reservada à consciência. Münsterberg sugere, ainda que de forma incipiente, a existência de lacunas nas frenéticas mudanças de plano no cinema. Talvez tenhamos aí uma primeira sugestão do espaço extra-imagem na teoria do cinema.

Um teórico entusiasta do close-up, o cineasta húngaro Béla Balazs (1884-1949), em texto de 1943 (2008), avança mais um pouco na discussão ao compreender o recorte da imagem cinematográfica (o plano) como uma síntese que é, por sua vez, mutável e viva, que se funde na consciência do espectador com a representação de um todo coerente. Balazs acrescenta os efeitos sonoros como referenciais na representação cinematográfica, apontando, assim, para um fora de campo da imagem, para outra dimensão do quadro, ainda não tomada como parte 'visível'. 
A famosa proposição do francês Bazin (1918-1958) de que a "moldura na pintura é centrípeta e a tela do cinema é centrífuga" (1991, p. 173), ecoa até hoje ${ }^{2}$. Segundo Bazin, no quadro pictórico a imagem age em profundidade, para dentro, ao contrário da tela no cinema, em que a imagem gira e salta para fora do quadro. O interessante nesse artigo de Bazin é a afirmação de que existe uma "virtualidade secreta" na tela cinematográfica, ainda que o autor não defina o que seja este extra-campo. Foucault (1999), ao realizar análise da representação no quadro $A s$ Meninas de Velásquez, exalta a invisibilidade. Segundo ele, o pintor olha para o espaço vazio em que o espectador, situado fora do quadro, observa a cena. Esse lugar fora de cena, que é revelado pelo reflexo do espelho localizado no centro do quadro, é apontado por Foucault como o que constitui o "verso da cena" (p. 13).

A primeira tentativa de classificar o extra-campo parece ter sido do cineasta norte-americano Nöel Burch (que o denominou de "espaço-off”) em obra publicada em 1969. Burch (1992) define seis "segmentos" para o extra-campo: os quatro cantos do retângulo da tela, o que está localizado atrás da câmera e aquilo que está localizado atrás do cenário. Anos mais tarde, Tarín (2006), propõe uma tipologia mais complexa para o estudo e conceito do extra-campo com a criação de modalidades como movimento de câmera, quadro vazio, re-enquadramentos, entradas e saídas de quadro, olhares para a câmera e o componente sonoro.

O teórico de cinema francês Jacques Aumont, autor contemporâneo que mais sistematicamente tratou do extra-campo (1993, 2004), denomina-o como o campo da imagem de espaço plástico (referência óbvia à tela nas artes plásticas). O espaço plástico compreende, assim, a superfície, as cores, a luminosidade, os elementos gráficos e a matéria que constitui a imagem, como o grão ou o pixel no audiovisual. Esse espaço é, invariavelmente, determinado pelo enquadramento da câmera e é recoberto por uma moldura que limita fisicamente as dimensões da composição da imagem. Uma das tantas contribuições de Aumont ao estudo dos quadros foi a de perceber que o termo ‘enquadramento' é mais apropriado ao cinema do que, propriamente, o termo quadro. A câmera de cinema (de audiovisual, enfim), por conta da duração, enquadra e re-enquadra a imagem incessantemente, diferentemente da pintura em que tudo "surge" e permanece no quadro, em que a cena busca o instante pregnante ${ }^{3}$. Enquadramento, por outro lado, pressupõe mobilidade e sucessão de olhares, de quadros. A cena segue, assim, o instante qualquer. O audiovisual enquadra e o faz de diferentes formas. Para Aumont (2004), no cinema clássico, por exemplo, o enquadramento tende à centralização das formas, enquanto no cinema moderno ao desenquadramento e, no vídeo, à sobreposição de frames.

O extra-campo para o cineasta francês Bonitzer (2007) é um campo cego, espécie de buraco negro que aspira os objetos para seu centro de gravidade. A visão parcial de um personagem, paisagem ou objeto situa-se, para este autor, "na intersecção entre o espaço e o tempo 
cinematográficos", na medida em que produz o efeito de suspensão temporal na imagem: desejo de ver mais, o que antecede ou sucede a imagem. O espectador de cinema, apesar da montagem de planos fragmentados e aleatórios, tende a unificar o campo, a criar, imaginariamente, a continuidade e o ambiente maior entre planos isolados da cena. O autor cita o "efeito-Kulechov" como exemplo do desejo do espectador em produzir sentido e narrativa frente a duas imagens aleatórias que são, por sua vez, montadas em sequência. Esse "efeito" refere-se a experiência empírica realizada pelo cineasta e teórico Lev Kulechov em 1917 quando juntou, via montagem, o mesmo plano com um ator (com a mesma expressão) com outros três planos aleatórios: um caixão, um prato de comida e uma criança sorrindo. A experiência provou que a platéia era levada a criar relações e sentidos diversos quando o plano do ator era justaposto aos outros planos. A experiência de Kulechov tinha por objetivo legitimar, cientificamente, a montagem no cinema

O cineasta russo Lev Kulechov (1899-1970) desenvolveu, para reforçar a sua tese de montagem, o conceito de "geografia criativa", que vem a ser o ambiente imaginário construído pelo espectador a partir de pedaços recortados do cenário. $\mathrm{O}$ espectador imagina, assim, o contexto espacial da cena, o que não está propriamente enquadrado. Nesse sentido, para Bonitzer (2007), a montagem dos planos é responsável por apagar e refazer, continuamente, o campo ausente do quadro.

Em uma análise mais psicológica da recepção da imagem cinematográfica, o cineasta francês Bellour (1991) acredita que as passagens nas imagens em movimento, ao contrário da imagem isolada na fotografia, se dão por intermitências, descontinuidades e lapsos temporais. A partir daí, podemos refletir sobre o efeito neurológico da "persistência da retina"4 , que possibilitou criar no espectador do cinema a ilusão do movimento por meio da sucessão de fotogramas, ou seja, através de imagens fixas. Esse efeito cognitivo demonstra o poder "lacunar" da imagem cinematográfica. Entre um fotograma e outro, existe um intervalo, uma falta. $\mathrm{O}$ fotograma que o cérebro codifica já passou no rolo do projetor. Esse dado da recepção da imagem do cinema leva-nos a cotejar o extra-campo como a consciência mesma do ato cinematográfico. Ora, se o cérebro busca o rastro da imagem que já passou na retina, o conceito de extra-campo configura-se como um mecanismo fundante na imagem-cinema.

No cinema contemporâneo ocorre o que Oliveira Jr. (2010) denomina de "cinema de fluxo", , o rompimento com a mise-en-scène clássica, herdada do teatro do século XIX, em que a representação se baseava no plano cinematográfico. No cinema de fluxo, a câmera não corta, mas (re)enquadra, desfoca e perde o personagem durante a ação. A construção do plano sugere que existe algo mais em torno da imagem. Para o autor, seria uma nova modalidade de quadro no audiovisual contemporâneo. Coelho (2005), por sua vez, utiliza o conceito de "planar na imagem", 
desenvolvido por Greenberg (1996) ao retomar a estética barroca em oposição à perspectiva clássica. Na arte barroca, segundo Greenberg, existia a noção de dentro e fora da imagem, algo que se perde com a imersão do observador no centro do quadro renascentista. $\mathrm{O}$ efeito de planar sobre a imagem levaria, na leitura de Coelho, à percepção do extra-campo no quadro pictórico, da continuidade do quadro para fora da tela (mais ou menos a mesma formulação de Bazin).

Queiroz Filho (2009) na sua dissertação aborda a construção da geografia imaginária no cinema e trata o extra-campo como componente inerente da memória do espectador. Segundo Queiroz, o espectador ao ver os locais fílmicos recupera outra imagem, subjetiva e fora-de-quadro, daquele local. $\mathrm{O}$ autor relaciona o extra-campo com termos como indício e traço da memória. Também em pesquisa de mestrado, Goulart Barbosa (2006), apoiado em Lacan e Eisenstein, conclui que o trabalho analítico na psicanálise opera no fora de campo da visão (a invisibilidade do analista, sentado atrás do paciente) e na montagem da linguagem/fala (o paciente, deitado no divã, fala no "vazio"). Barbosa relaciona a identificação do espectador com o olhar da câmera/cineasta: um olhar que não é seu, com o olhar invisível do outro, do analista. O analista olha o olhar do paciente no vazio. Conforme o autor, o enquadramento no processo psicanalítico faz-se em torno das imagens, no campo invisível da interpretação. Recupera o conceito de gesto em Lacan, que seria um “dar-se a ver". O gesto, contudo, deixa rastros. O rastro é, conforme a leitura do autor e em diálogo com Lacan, uma "falha" no olhar do cineasta e do paciente no processo da linguagem.

Kosmiski (2008), na sua pesquisa de doutorado, investiga a oposição que se constitui historicamente entre a visão ciclópica (renascentista) e a visão panorâmica (moderna), para traçar atualidades e variações dessas culturas visuais no mundo contemporâneo, principalmente no material distribuído na televisão. A autora resgata a etimologia dos panoramas (espetáculos visuais pré-cinema), que, segundo ela, têm relação cultural com a visão propiciada pelas janelas dos trens e com as salas de cinema na modernidade: ver tudo em movimento, junto com a máquina, em velocidade e através de quadros móveis.

Os cineastas também discutem e criam denominações para o extra-campo. O cineasta russo Dziga Vertov (1896-1954), por exemplo, propõe, dentro do seu "cine-olho" - o olhar da câmera, do aparelho - o conceito de intervalo entre as imagens. Em oposição à montagem naturalista e em continuidade do cinema clássico hollywoodiano, Vertov defende uma montagem que evidencie a diferença entre as imagens, ou seja, um intervalo, um salto temporal dentro do movimento dos planos. O intervalo é o que separa dois fragmentos (planos) do filme e que só pode ser realizado dentro do aparelho. Segundo Vertov, se existe o intervalo entre os planos, pode haver, um limiar, na duração, entre o campo visível e o invisível em cada imagem (VERTOV, 1973). 
O também cineasta e teórico russo Sergei Eisenstein (1898-1948) (2002) identificou na cultura oriental, sobretudo na japonesa, a montagem de significantes para produzir ideias e conceitos. Essa construção conceitual de imagens foi a base da sua teoria de montagem. A cultura japonesa, segundo o cineasta, possui formas cinematográficas tais como o ideograma. A escrita japonesa é gráfica e conceitual: duas imagens significam um verbo, uma ação, como por exemplo: cachorro + boca $=$ latir ou boca + criança $=$ gritar . Eisenstein desestabilizou a noção visual clássica ao buscar as linhas e formas sobrepostas, descontínuas. Na sua obra cinematográfica, não somente a montagem entre as imagens é conflitante, como a montagem interna ao quadro subverte a lógica naturalista. Eisenstein foi um grande crítico dessa lógica pois considerava que a montagem não se resumia na ligação e justaposição de planos. Com sua posição entrava em choque com os estudiosos da montagem do seu tempo - principalmente Kulechov e Pudovkin. A escola de montagem de Kulechov, por exemplo, tratava cada plano cinematográfico como uma peça, um tijolo que deveria ser montado cronologicamente para compor a narrativa.

A “dramaturgia da forma” (2002), proposta por Eisenstein, consiste em desarmonizar a composição dos objetos em volumes, escalas, tonalidades e luzes, isto é, a dialética dentro da própria superfície do quadro. A proposta de Eisenstein, de uma montagem interna ao plano, pode ser muito produtiva no sentido de confrontar os limites do quadro e evidenciar outros "enquadramentos" dentro da imagem.

Outro cineasta que flerta com a descontinuidade temporal na montagem e, principalmente, com a questão da visualidade da imagem é o franco-suíço Jean-Luc Godard ${ }^{6}$. Seus filmes-ensaio, que questionam, desde a década de 1960, o estatuto da imagem ajudam a refletir sobre o entrecruzamento do campo e do extra-campo no audiovisual. Ao analisar a obra de Godard, Aumont (2004) chama a atenção para o uso de "intervalos" entre as imagens (como aqueles pensados por Vertov), principalmente no filme Passion, realizado em 1982. Nesse filme em especial, o cineasta lança mão de telas brancas ao longo da narrativa, que Aumont interpreta como a possibilidade de "ver a passagem do invisível ao visível” (Idem, p. 57). Ainda sobre a obra de Godard, Dubois (2006) ressalta o uso do suporte do vídeo como meio de mutação da tela, seja ela pintada, escrita ou filmada. Esse procedimento estético em Godard, que Dubois chama de “sobre-impressões", possibilita a inscrição e a fusão (eletrônica) de diversas imagens no mesmo quadro, confrontando, assim, o começo e o final da imagem. Peixoto (1996), no entanto, ao dialogar com as experiências videográficas de Godard, considera que o extra-campo no vídeo não existe, pois "o exterior da imagem é substituído pelo intervalo entre dois enquadramentos" (p. 209). 
Este estado da arte, segundo nosso entendimento, permite delinear perspectivas teóricas recorrentes sobre o estudo e a significação do conceito de extra-campo, e, sobretudo, identificar duas linhas principais de entendimento: a primeira, compreende o extra-campo como o “entre-imagem", isto é, imagem de intervalo, lacunar, que está entre outras imagens do quadro. Essa visão é compartilhada por Bellour, Vertov, Eisenstein e Musterbeng. A segunda linha, vê o extra-campo como uma imagem "centrífuga", ou seja, imagem para fora da imagem, que extrapola o enquadramento. Nessa linha estão Bazin, Crary, Bonitzer, Deleuze e Godard.

Diante de tantos entendimentos sobre o extra-campo, acreditamos que nenhuma imagem se esgota no limite do enquadramento a que foi submetida. $O$ que existe são, portanto, materialidades, subjetividades e formas distintas de se ver no vasto universo das imagens técnicas. O “espaço" da obra de arte, como afirma Didi-Huberman (2010), é sempre simbolicamente inacessível, seja pelo excesso ou pela falta. O filme, antes de existir, vive na imaginação do cineasta e depois, adquire sobrevida na memória do espectador. Ele é lampejo, para quem fecha os olhos e vê. O que, justamente, o ilusionista francês e um dos precursores do cinema George Meliès (1861-1938) viu nos filmetes dos Lumiére, nos primórdios do cinema: o vento, invisível, balançando as folhas das árvores.

\section{DIALÉTICA DO VISÍVEL}

A experiência estética mobiliza-nos de tal forma que nos reconhecemos, nos vemos na imagem e somos, ao mesmo tempo, olhados por ela. Da mesma forma, somos levados a outros lugares, remotos e imaginários, nunca percorridos, por meio da imaginação. As imagens existem porque olhamos para elas. As imagens suplicam e retribuem olhares.

A aura, em Benjamin (1989), é a presença de algo que está distante e o rastro é a presença de algo que está perto, mas que já está em outro lugar. A aura para o autor é: “uma figura singular, composta de elementos espaciais e temporais, a aparição única de uma coisa distante, por mais próxima que ela esteja” (p. 101). Para exemplificar Benjamin utiliza uma imagem: imagina-se sentado em uma varanda, em uma tarde de verão, observando montanhas no horizonte que projetam a sombra sobre ele. Benjamin diz "respirar" a aura das montanhas, sentir a sua presença. No texto em que discute a reprodução técnica, Benjamin (2012, p. 92) descreve a aura como "um estranho tecido fino de espaço e tempo".

A visão da aura como algo abstrato e descolado do real pode levar à falsa ideia de alienação e dar uma dimensão mística ao conceito proposto por Benjamim. Nada mais falso: a busca pela aura é, justamente, a posição, política e ética, do pesquisador em ultrapassar a aparência 
da matéria, dos objetos e da imagem enquanto mercadoria. Ou seja: ir além da imagem. É propor, na visão de Didi-Huberman (2010), a recusa à tautologia ${ }^{7}$, isto é, perceber a imagem somente como imagem dotada de volume, tamanho, peso, enfim, como mero objeto.

Com o seu conceito de aura, Benjamin discute e critica a reprodução técnica e sua capacidade de tornar cada vez mais cômodo e descartável captar e possuir os objetos, as imagens. A busca pela aura, ao contrário, é a procura em não se deixar seduzir pela ilusão do capital, mas descobrir o instante mágico e invisível das coisas. Como fios de nuvens no céu, que vão se desfazendo até sumirem. Ultrapassar, assim, o invólucro que a imagem banalizada mascara. A percepção da aura opõe-se ao hábito mecânico e redundante da vida cotidiana. Quando Benjamin (2012) sugere que um edifício pode ser "habitado" de dois modos: o modo utilitário, funcional e o modo perceptivo, estético, ele, talvez, quisesse assinalar os dois modos possíveis de interação do sujeito com as suas edificações, entendidas como construções simbólicas, tanto no sentido social como no artístico.

Benjamin analisa que os relacionamentos com as imagens se modificam a partir da reprodução técnica. Se antes, a pintura secular, era para ser contemplada, isto é, "aquele que se recolhe perante uma obra de arte submerge nela, entra nesta obra", o cinema - o novo dispositivo perceptivo - representa a distração, o choque cognitivo, do qual o sujeito "submerge em si a obra de arte". O sujeito, na era da reprodutividade técnica, age sobre as imagens e junto com elas. A mesma relação que Benjamin (1989) estabelece entre o mago (analogia para o pintor) e o cirurgião (analogia para o cineasta). Enquanto o mago age à distância do corpo e da realidade, o cirurgião, seu polo oposto, intervém na realidade com equipamentos, mediado pela técnica.

Ao analisar a Paris de fins do século XIX, cenário do flâneur $^{8}$, Benjamin constata a profusão de novas e velhas imagens que coexistem e o mais importante aqui: que a noção de interior e exterior, público e privado, perto e longe, torna-se porosa, transitória. Benjamin (2007), sobre essa nova relação perceptiva mediada pela técnica, descreve os espetáculos de panoramas, que reproduzem, artificialmente, a paisagem "natural" montada dentro de grandes galpões; o uso do ferro, material próprio para as estradas de ferro que são utilizados na arquitetura de ambientes internos como galerias e salas de exposições; as residências burguesas que se tornam "o universo", o "casulo" do morador, com equipamentos como escritório, bar e toca-discos e, finalmente, os bistrôs repletos de espelhos, onde não se sabe "se estamos saindo ou entrando" (2007, p. 25). Não podemos esquecer que o cinema, naquele momento, é o meio que fortalece este modelo e relação, pois projeta o mundo, fora, dentro de uma sala escura. "Magia do limiar", diria Benjamin (Idem, p. 39). Podemos montar um grande inventário de "lugares" que jogam com o sentido limiar, entre o dentro e o fora: vitrais das igrejas, porta giratória nas agências bancárias, automóvel em movimento na autoestrada, varanda dos apartamentos, um livro aberto deixado em cima de uma mesa. 
O conceito de aura é, aqui, complementar e está posto para criar, justamente, o contraponto com o conceito que, de fato, nos interessa: o rastro. A aura e o rastro são conceitos vinculados à questão do tempo e acreditamos que nos permite entender o deslocamento dos planos audiovisuais entre o visível e o invisível.

A aura, como imagem nostálgica, de valor transcendente, que, na visão de Benjamin (2012), se distancia, se perde na paisagem dominada pela técnica, é a imagem remota do que já passou, mas, por outro lado, essa imagem, possibilita novas percepções e pode reaparecer, aos olhos do espectador, em forma de aparição e memória, ou seja, em forma de sensações que deslocam e tiram o espaço físico e objetivo. Para uma obra de arte produzir aura, na opinião de Didi-Huberman (2010), ela precisa não ter contornos, limites, ocultar mais do que mostrar e precisa, ainda, revelar uma "presença não real" ao espectador.

Tanto o rastro como a aura produz, no sujeito, o sentimento de ausência, de perda, do que não está, concretamente, presente aos olhos do espectador. Por isso, aura e rastro estão relacionados à dimensão temporal das coisas no pensamento de Benjamin (2007), seja da história, dos objetos e das imagens. A técnica impõe-se de tal forma na modernidade que Benjamin procura ver o que estava fora da visão, o que estava, aparentemente, ausente, nas entrelinhas e sobreposto ao presente mais imediato.

Na narrativa das distâncias de Benjamin, a aura traz, assim, a sensação do passado, enquanto que o rastro se configura como as marcas do passado e, ao mesmo tempo, com a projeção do futuro, pois o quê e quem o provocou já passou e está em outro lugar. Ginzburg (2012), que vê o rastro como a "potência latente do que não foi dito" (ou visto), reforça a condição temporal implicada no conceito de Benjamin e pondera

[...] Observar um rastro no chão, um bilhete de uma viagem feita no passado, uma fotografia, assim como contemplar um espaço em ruína, pode envolver o esforço de pensar na existência à luz das perdas: são situações em que um fragmento, um resto do que existiu pode ajudar a entender o tempo como processo, em que o resto é também imagem ambígua do que será o futuro (p. 109).

E complementa: tratar um objeto como rastro "implica admitir que ele tem mais de um significado possível. Além de sua presença imediata, nele se encontra uma cifra, que pode ser tomada como condição para entender o que houve ou supor o que haverá" (Idem, p. 112). A inscrição dos rastros nas imagens técnicas pode ser imaginada de diferentes formas. Na fotografia, por exemplo, existe o rastro do instante, daquele momento que se seguiu a sua "petrificação". No cinema, há o rastro da filmagem, que é retomado na fase de montagem do material bruto. $\mathrm{Na}$ transmissão ao vivo da televisão, habitam os rastros de pessoas e lugares longínquos, dentro da 
sala de estar. Na tela do computador, temos rastros de "janelas" que se sobrepõem umas às outras, tal qual um palimpsesto audiovisual. O próprio significado da palavra "imagem" está associado aos rastros ou indícios do real: "a imagem é a semelhança ou o vestígio das coisas, que se pode conservar independente das próprias coisas" (ABBAGNANO, 1982, p. 511).

Neste cenário, a imaginação é um aspecto importante que pode apontar para muitas direções - tanto para o passado como para o futuro - e a sua "presença", material e imaterial, confundir-se com a sua própria imagem, pois o que é virtualidade e abstração pode ou não se realizar. Ou ainda, vai se realizar. A imaginação, como concretização possível ou pretendida da imagem, não deixa de ser "menos" imagem, apenas, uma imagem de outra natureza.

Podemos imaginar, por exemplo, imagens e planos, em uma cena bem prosaica: começa com um plano conjunto de uma sala de estar. Podemos ver uma mesa e duas pessoas, um homem e uma mulher, sentados, tomando café e lendo um jornal. Nesse primeiro plano, não vemos o cachorro que está dormindo, embaixo da mesa. A campainha da porta toca. No plano seguinte, é revelado o cachorro, que acorda e começa a latir, histérico. No terceiro plano, há uma visão geral da sala, o homem levanta-se da mesa e vai até a porta. A mulher o acompanha com o olhar. O cachorro late ainda mais. O homem abre a porta. No plano seguinte, um rosto do homem, que vê uma carta que foi deixada em cima do tapete da porta. Em outro plano, é visível detalhes da carta.

No primeiro plano, o cachorro é a presença-ausente do quadro: ele está próximo, debaixo da mesa, mas ausente do quadro. No segundo plano, o cachorro torna-se presente e o som da campainha - fora de quadro - anuncia que alguém está próximo, além da porta. No plano seguinte, geral, todos os elementos - homem, mulher e cachorro - estão presentes, menos a presença-ausente de quem tocou a campainha. No quarto plano, somente o homem vê a carta que foi colocada em cima do tapete. A carta, agora, é a presença-ausente do plano. No último plano, a carta aparece como rastro de quem a deixou - e de quem, antes, a escreveu - e que já está em outro lugar, distante ou talvez ainda muito próximo da casa do casal.

A presença é, para Did-Huberman (2010), uma cisão do ver: vejo a imagem e ela, por sua vez, também me olha. A posição em relação à imagem que devo tomar a partir daqui é: a imagem não se reduz à simples objeto inanimado, descartável e pragmático. A presença da imagem não está só nela, no momento da sua visualização. A imagem imagina a imagem que ela poderia ser e imaginamos junto, dentro e fora dela. Um filme muito apreciado, por exemplo, que nos acompanha por décadas, é mais invisível que visível. Não preciso revê-lo, pois suas imagens me assombram quando menos espero, como um vento repentino que desperta as folhas das árvores. A criação (científica e artística) é algo como encontrar essas imagens atemporais, anacrônicas, que estavam escondidas, que crescem sem que possamos controlar ou perceber e, aí sim, podemos tocar a sua presença, diante dos olhos, como aura, no sentido benjaminiano. 


\section{CONSIDERAÇÕES FINAIS}

Se o tempo presente é a cisão entre passado e futuro na "imagem dialética" de Benjamin (rastro que projeta o futuro e aura que traz o passado modificado), podemos tensionar esse tempo com o movimento dos planos no cinema e, o mais importante, sugerir o extra-campo como dimensão temporal da imagem, que se abre no plano presente, ou seja, no plano visível e espacializado, em diferentes direções possíveis de passado e de futuro.

Deleuze criou o conceito de "imagem-cristal" para dialogar com a "imagem-tempo", simultânea, que não está condicionada ao movimento atual do corpo no espaço: movimento com objetivo, com ponto de partida e chegada. A imagem do cristal está relacionada ao tempo sobreposto da memória. A imagem presente está sempre passando, ela não está, dessa forma, no tempo presente, atual. Está na mudança de tempo entre percepção e lembrança, no que passou e no que virá. Na sua obra, Benjamin analisa que o passado não deve ser apagado em função da ilusão do futuro e propõe os conceitos de "agoras" do tempo presente e "explosão do tempo" no mesmo acontecimento, na mesma imagem, como formas de ultrapassar, no pensamento, o presente.

Para fugir do determinismo do espaço, ou seja, da visão tautológica em cujo contexto entende-se a imagem com começo e fim, reduzida aos seus limites físicos e reais, buscamos pensar o extra-campo pelo prisma do tempo ao estabelecer contato, principalmente, com os conceitos de aura e rastros em Benjamin. O "espaço" da obra de arte, como afirma Didi-Huberman (2010), é sempre simbolicamente inacessível, seja pelo excesso ou pela falta. $\mathrm{O}$ filme, antes de existir, vive na imaginação do cineasta e depois, adquire sobrevida na memória do espectador. Ele é lampejo, para quem fecha os olhos e vê.

Retornamos à obra de Aumont (2004, p. 40), que nos auxilia a entender que

se o campo é a dimensão e a medida espaciais do enquadramento, o fora-de-campo é a sua medida temporal, e não apenas de maneira figurativa: é no tempo que se manifesta os efeitos do fora-de-quadro. O fora-de-quadro como lugar do potencial, do virtual, mas também do desaparecimento e esvaecimento: lugar do futuro e do passado, bem antes de ser o do presente.

Conseguimos, agora, tatear a nossa aposta ou espiar dentro do cristal: no plano que vemos, nesse passado sempre atualizado, reconhecemos os elementos e corpos que já vimos antes, em outra cena e, ao mesmo tempo, essa cena vai aparecer, no futuro, modificada, sob outro ângulo, mais à frente na narrativa cinematográfica. A imagem que está no plano passado e no plano futuro configura-se, assim, como a presença do tempo do extra-campo. 


\section{NOTAS}

1 Este artigo insere-se no escopo de pesquisa de doutorado em Programa de Pós-graduação em Comunicação com bolsa Capes/PROSUP.

2 Neste artigo intitulado "Pintura e Cinema", Bazin analisa a transferência dos quadros do pintor Van Gogh para o cinema, mais especificamente no curta-metragem Van Gogh de Alan Resnais (1948). O artigo de Bazin marca, por exemplo, o ponto de partida para a análise que Aumont (2004) realizará sobre a relação entre pintura e cinema.

3 A expressão "instante pregnante" foi criada por Lessing em 1766 para designar a pintura "encenada", artificial na ação da cena representada. Esse instante ou momento é a essência do acontecimento ficcional, o momento decisivo, o clímax da cena. Aumont (2004) traduz esse instante como "instante mais favorável" da representação.

4 Segundo estudiosos da área de psicologia e neurologia, o cérebro não acompanha a velocidade dos fotogramas (24 quadros por segundo), o que faz com que, enquanto uma imagem é vista, a outra já se pronuncie na retina. Esse efeito de encadeamento brusco dos fotogramas produz a ilusão de movimento que gera a imagem cinematográfica.

5 Exemplos de "cinema de fluxo" citados pelo autor: Cidade de Deus (2002) de Fernando Meirelles e Gerry (2002) de Gus Van-Sant.

6 Godard fez parte, nas décadas de 1960 e 1970, de um grupo militante-artístico denominado de "Dziga Vertov".

7 Tautologia é, na retórica, a redundância da linguagem, do sentido. Trocar, no senso comum, "seis por meia dúzia". O pintor belga Magritte (1898-1967), no quadro A Traição das Imagens (1926), demoliu o conceito de tautologia ao desenhar um cachimbo e escrever embaixo do desenho: "isto não é um cachimbo". Imagem e texto em colisão.

8 O personagem do flâneur aparece em vários momentos da obra de Benjamin. Ele é inspirado nas narrativas publicadas por Poe e Baudelaire para descrever a experiência de personagens tipicamente urbanos do século XIX, como o boêmio, o mendigo e a prostituta a partir do olhar de um personagem que "flana" pelas ruas das grandes cidades (neste caso a experiência em Londres e Paris da época) sem compromisso, ora com um olhar de fora, criando um distanciamento sobre o que vê, ora com um olhar de dentro, parte do que ocorre na cidade.

\section{REFERÊNCIAS}

ABBAGNANO, N. Dicionário de Filosofia. Lisboa, PT: Mestre Jou, 1982.

AUMONT, Jacques. O Olho interminável - Cinema e Pintura. São Paulo: Cosac Naify, 2004.

. A Imagem. Campinas, SP: Papirus, 1993.

BALÁZS, B. The close-up and the face of man. IN: DALLE VACCHE, A. (Ed.). The Visual Turn: classical film theory and art history. New Jersey: Rutgers University Press, 2003. Pp. 15-6.

BARBOSA, P. B. G. Um Olhar impossivel: construção psicanalítica e montagem cinematográfica. 89 f. Dissertação (Mestrado em Psicologia), Universidade de Brasília, Brasília, 2006. 
BAZIN, A. Cinema: Ensaios. São Paulo: Brasiliense, 1991.

BENJAMIN, W. Passagens. Belo Horizonte; São Paulo: Editora UFMG e Imprensa Oficial do Estado de São Paulo, 2007.

. Sobre alguns motivos em Baudelaire. In: BENJAMIN, Walter; HORKHEIMER, Max; BONITZER, P. El Campo ciego: ensayos sobre el realismo en el cine. Buenos Aires: Arcos Editor, 2007.

BURCH, N. Práxis do Cinema. São Paulo: Perspectiva, 1992.

CLARY, J. A visão que se desprende: Manet e o observador atento no final do século XIX. IN: CHARNEY, L.; SCHWARTZ, V. (Org.) O cinema e a invenção da vida moderna. São Paulo: Cosac Naify, 2004.

COELHO, R. B. Entre, tem ar. O espectador dentro e fora do quadro. Dissertação (Mestrado em Mestrado em Artes Visuais da Escola de Belas Artes) - UFMG, 2005.

DELEUZE, G. Imagem-Movimento. São Paulo: Brasiliense, 1989.

. Imagem-Tempo. São Paulo: Brasiliense, 2005.

DIDI-HUBERMAN, G. O que vemos, o que nos olha. São Paulo: Editora 34, 2010.

DUBOIS, P. Cinema, vídeo, Godard.São Paulo: Cosac Naify, 2006.

EISENSTEIN, S. A forma do Filme. Rio de Janeiro: Zahar, 2002.

FOUCAUlT, M. As Palavras e as coisas. São Paulo: Martins Fontes, 1999.

GINZBURG, J. (Orgs.). Walter Benjamin: Rastro, aura e história. Belo Horizote: UFMG, 2012.

GOLIOT-LETÉ, A.; JOLY, M.; LANCIEN, T.; outros. Dicionário de Imagem. Lisboa, Portugal: Edições 70, 2011.

GREENBERG, C. Arte e cultura: ensaios críticos. São Paulo: Ática, 1996.

KILPP, S. A Traição das Imagens: espelhos, câmeras e imagens especulares em reality shows. Porto Alegre: Entremeios, 2010.

. Audiovisualidades do voyerismo televisivo: apontamentos sobre a televisão. Porto Alegre: Zouk, 2008.

KOSMINSKI, S. O olhar inocente é cego: a construção da cultura visual moderna. Tese (Doutorado em Artes e Design), Pontifícia Universidade Católica do Rio de Janeiro, Rio de Janeiro, 2008.

MACHADO, A. O sujeito na tela. Modos de enunciação no cinema e no ciberespaço. São Paulo: Paulus, 2007. 
MACHADO, I. de A. Sensus Comunnis: para entender o espaço acústico em seu ambiente sensorial ressonante. E-Compós: Brasília, V.14, N 3, set/dez. 2011.

MÜNSTERBERG, H. A atenção; a memória e a imaginação e as emoções. In: XAVIER, I. (Org.). A Experiência do Cinema: ontologia. 4. ed. Rio de Janeiro: Edições Graal; Embrafilmes, 2008. p. $25-54$.

OLIVEIRA JUNIOR, L. C. de. O cinema de fluxo e a mise en scène. Dissertação (Mestrado em Ciências da Comunicação), Universidade de São Paulo, Fundação de Amparo À Pesquisa do Estado de São Paulo, SP, 2010.

PARENTE, A. (Org.). Imagem-Máquina. A Era das Tecnologias do Virtual. São Paulo: Editora 34, 1996.

PEIXOTO, N. B. Paisagens Urbanas. São Paulo: Senac e Marca D'Água, 1996.

QUEIROZ FILHO, A. C. Vila-Floresta-Cidade: território e territorialidades no espaço fílmico. Dissertação (Programa de Pós-Graduação em Geografia), Unicamp, Campinas, SP, 2009.

VERTOV, D. El cine ojo. Madrid, Es: Fundamentos, 1973.

TARÍN, F. J. G. Discursos de la ausencia. Elipsis e fuera de campo en el texto fílmico. Valencia, Espanha: Ediciones de la Filmoteca, 2006.

XAVIER, I. (Org.). A Experiência do Cinema. Rio de Janeiro: 2008. 